Review

\title{
Bilayer dimensions and hydration of glycolipids
}

\author{
Derek Marsh* \\ Max-Planck-Institut für biophysikalische Chemie, 37070 Göttingen, Germany
}

\section{A R T I C L E I N F O}

\section{Article history:}

Received 5 August 2011

Received in revised form

28 September 2011

Accepted 12 October 2011

Available online 18 October 2011

\section{Keywords:}

Glycosyl diacylglycerol

Glycosyl dialkylglycerol

$\mathrm{X}$-ray diffraction

Chain tilt

Lipid area

Glycolipid hydration

\begin{abstract}
A B S T R A C T
X-ray diffraction measurements are available on a wide range of glycolipid multilamellar assemblies in excess water, but not at the defined water contents that are needed to derive bilayer dimensions. For lamellar crystalline phases and gel phases with untilted chains, or where the tilt angle is known, the crosssectional area per chain from wide-angle diffraction can be used to determine the area per lipid molecule at the bilayer surface. Using the lipid molecular volume from densitometry, it is then possible to obtain the bilayer thickness and hence, from the lamellar repeat spacing, the water layer thickness and degree of hydration of the lipid polar groups. This is done here by using the available data for bilayer-forming diacyl and dialkyl glycosylglycerols, and for certain glycosphingolipids. The lamellar crystalline phases of these glycolipids are largely anhydrous, and the degree of hydration of the lamellar gel phases is much lower than that of the corresponding phosphoglycerolipid gel phases. A point of current uncertainty is whether the chains in the gel phases of diacyl glycoglycerolipids are appreciably tilted, unlike their dialkyl counterparts.
\end{abstract}

\section{Contents}

1. Introduction

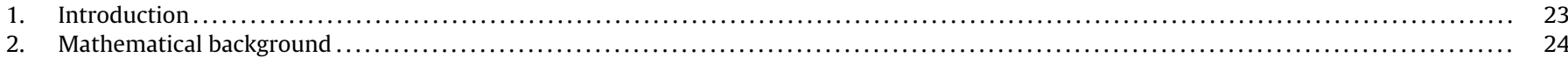

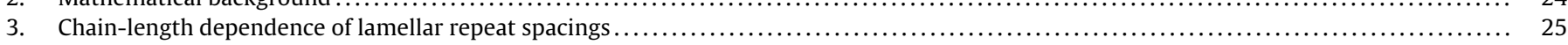

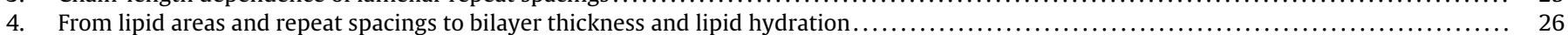

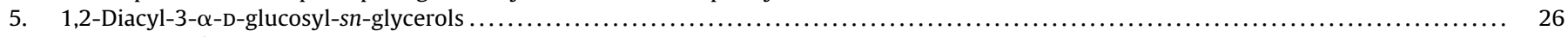

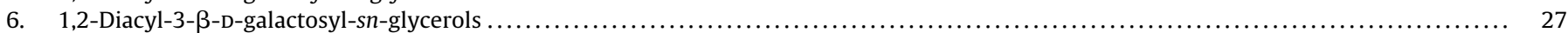

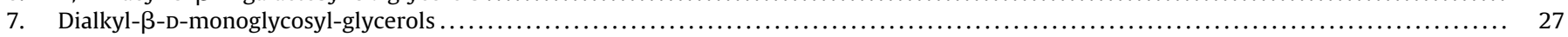

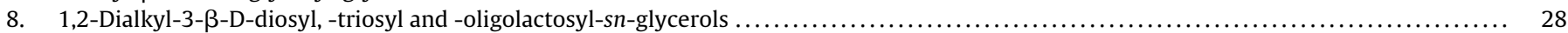

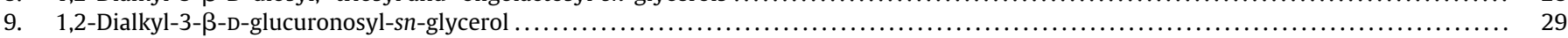

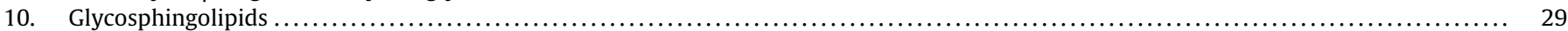

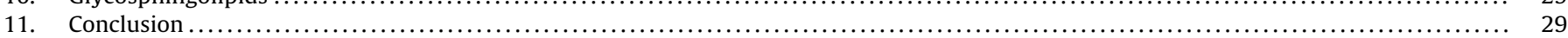

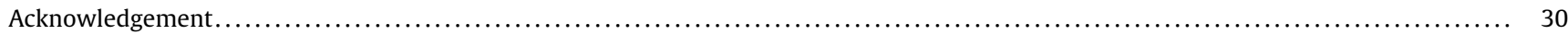

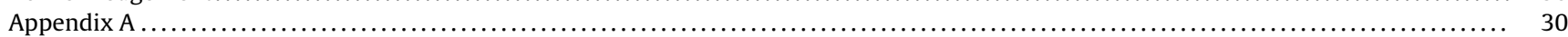

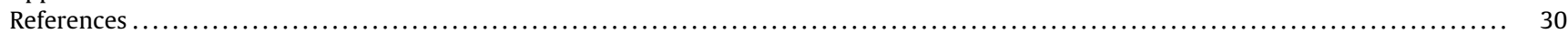

\section{Introduction}

Glycolipids are important constituents of nerve cell membranes, Gram positive bacteria, and also the photosynthetic membranes of all green plants. Compared with membrane phospholipids, however, they are less intensively studied from the biophysical standpoint. Whereas there are several detailed studies by X-ray diffraction on homologous series of diacyl or dialkyl glycosylglycerols in excess water (Sen et al., 1990; Mannock et al., 2001; Hinz

\footnotetext{
* Tel.: +49 551 2011285; fax: +495512011501

E-mail address: dmarsh@gwdg.de
}

et al., 1991; Köberl et al., 1998; Mannock et al., 2007), only in few cases has a systematic water dependence been performed (Turner et al., 1992; Minamikawa and Hato, 1997) to determine the bilayer membrane thickness by the approaches used originally for phospholipids (Luzzati, 1968; Tardieu et al., 1973). Possibly one reason for this is that the degree of hydration of glycolipid bilayers appears to be considerably lower than that of phospholipid membranes (Turner et al., 1992; Kulkarni et al., 1999), which is reflected in their higher chain-melting transition temperatures (cf. Cevc and Marsh, 1985). Lipid hydration affects not only the membrane phase state, but is also one of the primary determinants of bilayer-bilayer interactions, with associated implications for membrane fusion and cell-cell interactions. 


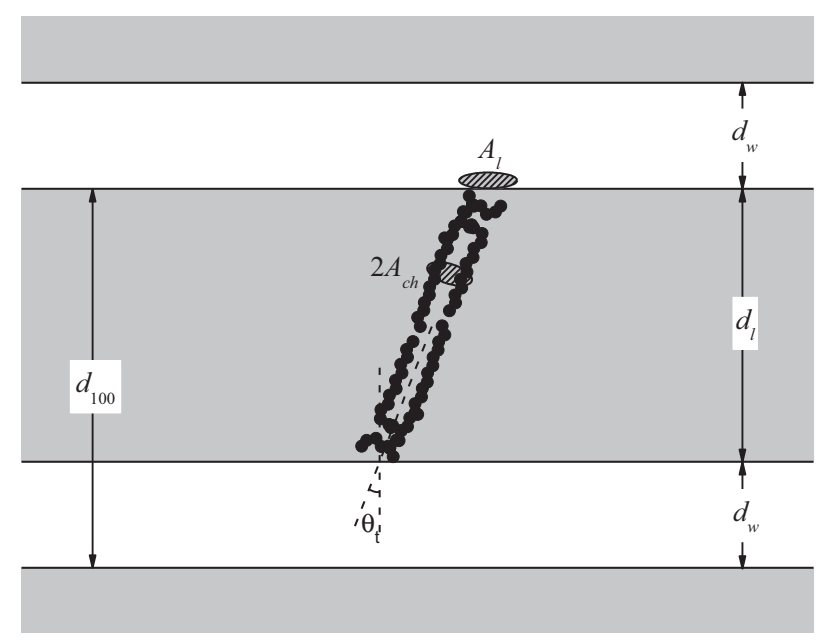

Fig. 1. Dimensions of hydrated lipid multibilayers. $d_{100}$ is the X-ray lamellar repeat spacing; $d_{1}$ and $d_{\mathrm{w}}$ are the lipid bilayer and water-layer thicknesses, respectively. $A_{1}$ is the area per lipid molecule in the plane of the bilayer. $A_{\mathrm{ch}}$ is the area per chain in the plane perpendicular to the chain axis, and $\theta_{\mathrm{t}}$ is the tilt of the chain axis from the bilayer normal, in gel or crystalline phases.

More recently, greater detail has been attained in defining the transverse structure of phospholipid bilayers by an in-depth analysis of the electron density profiles, and in some cases of the neutron scattering-length profiles (Nagle and Tristram-Nagle, 2000; Tristram-Nagle et al., 2002; Kucerka et al., 2008). Such measurements and analysis have yet to be developed to this degree of detail for glycolipids, which lack the electron-dense phosphate group that characterises the polar region of phospholipids. Although, a few determinations of electron density profiles have been performed for glycolipids or their mixtures with phospholipids (Ruocco and Shipley, 1986; Stinson and Boggs, 1989; Sen et al., 1990; McIntosh and Simon, 1994; Kulkarni et al., 1999).

Here, I combine the available data on X-ray long spacings, i.e., lamellar repeat distances, with those of the short spacings, i.e., chain-chain separations, of glycolipids in excess water to obtain information on the membrane thickness and polar head-group hydration in the crystalline lamellar phases and lamellar gel phases. In the absence of more extensive measurements of the types indicated above for phospholipids, this represents the current status for glycolipid bilayers and points to some of the uncertainties and opportunities for future work.

\section{Mathematical background}

The transverse dimensions of lipid bilayer membranes can be determined from the composition ( $n_{\mathrm{w}}$ waters per lipid) and the one-dimensional bilayer repeat distance, $d_{100}$, measured with small-angle X-ray scattering of stacked multibilayers (see Fig. 1). If $A_{\mathrm{l}}$ is the area per lipid molecule in the plane of the bilayer, the total volume (per lipid) of the bilayer stack is related to the multilayer repeat distance by:

$v_{1}+n_{\mathrm{w}} v_{\mathrm{w}}=\frac{A_{1} d_{100}}{2}$

where $v_{1}\left(=M_{1} \bar{v}_{1} / N_{\mathrm{A}}\right)$ and $v_{\mathrm{w}}\left(=M_{\mathrm{w}} \bar{v}_{\mathrm{w}} / N_{\mathrm{A}}\right)$ are the molecular volumes of lipid and water, respectively, and $N_{\mathrm{A}}$ is Avogadro's number. Following Luzzati (Luzzati, 1968; Tardieu et al., 1973), an anhydrous bilayer thickness, $d_{l}$, can be defined as:

$d_{1}=\frac{2 v_{1}}{A_{1}}$

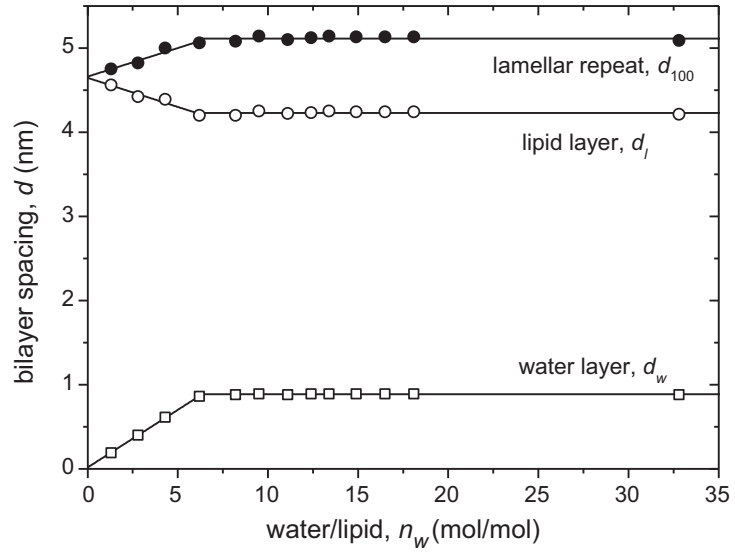

Fig. 2. Dependence of the bilayer and water-layer thicknesses $\left(d_{1}\right.$ and $\left.d_{\mathrm{w}}\right)$ and lamellar repeat distance, $d_{100}$, on water content, $n_{\mathrm{w}}$, in a swelling experiment with rac- $(0-12: 0)_{2} \mathrm{Glc} \beta$ Gro in the $L_{\beta}$ gel phase at $30^{\circ} \mathrm{C}$.

Data from Turner et al. (1992).

Then, by combining Eqs. (1) and (2), the X-ray repeat distance is related to the anhydrous lipid layer thickness by:

$d_{100}=d_{1}\left[1+\left(\frac{v_{\mathrm{w}}}{v_{\mathrm{l}}}\right) n_{\mathrm{w}}\right]$

Correspondingly, the thickness of the interlamellar water layer, $d_{\mathrm{w}}$ (assumed to contain all water), is given by:

$d_{\mathrm{w}}=d_{100}-d_{1}$

This idealised division of water and lipid into separate layers does not take account of water penetration into the lipid bilayer. Nonetheless, it does correspond to a well-defined physical location, namely the Gibbs dividing surface of the lipid-water interface.

According to Eq. (3), the anhydrous bilayer thickness, $d_{1}$, can be determined from the dependence of the repeat spacing on water content by using Eq. (3). The area per lipid, $A_{1}$, is then obtained from Eq. (2). For crystalline or gel phases with ordered chains, the tilt of the chains $\left(\theta_{\mathrm{t}}\right)$, relative to the bilayer normal, is then obtained from $A_{1}$ by using the geometric relation:

$\cos \theta_{\mathrm{t}}=\frac{2 A_{\mathrm{ch}}}{A_{\mathrm{l}}}$

where $A_{\mathrm{ch}}$ is the area/chain in the plane perpendicular to the chains (a two-chain lipid is assumed). The latter is obtained from the chain-chain spacings, in wide-angle X-ray scattering measurements.

Conventionally, the dimensions of fully hydrated lipid bilayers are determined by swelling experiments in which the limiting hydration, $n_{\mathrm{w}, \max }$, is obtained from the dependence on water content (see Fig. 2). Unfortunately, such water dependences are reported for relatively few glycolipids. Nevertheless, for phases with ordered chains, it is possible to invert the standard procedure, if the chain tilt or area per lipid is known from other means. It has been pointed out that gravimetric determinations of the type illustrated in Fig. 2 can overestimate $n_{\mathrm{w} \text {,max }}$, if not all water is accommodated uniformly between the multilayers but partly is incorporated in defect regions that do not give rise to sharp lamellar diffractions (Koenig et al., 1997; Nagle and Tristram-Nagle, 2000). This problem does not arise, however, if the limiting hydration is determined by other means, from measurements solely on fully hydrated samples. The latter approach is that adopted in the procedure used here.

Gel phases with untilted chains can be identified from the single, sharp chain reflection in the wide-angle region, which is a diagnostic feature of the untilted $L_{\beta}$ phase (see, e.g., McIntosh, 1980). 


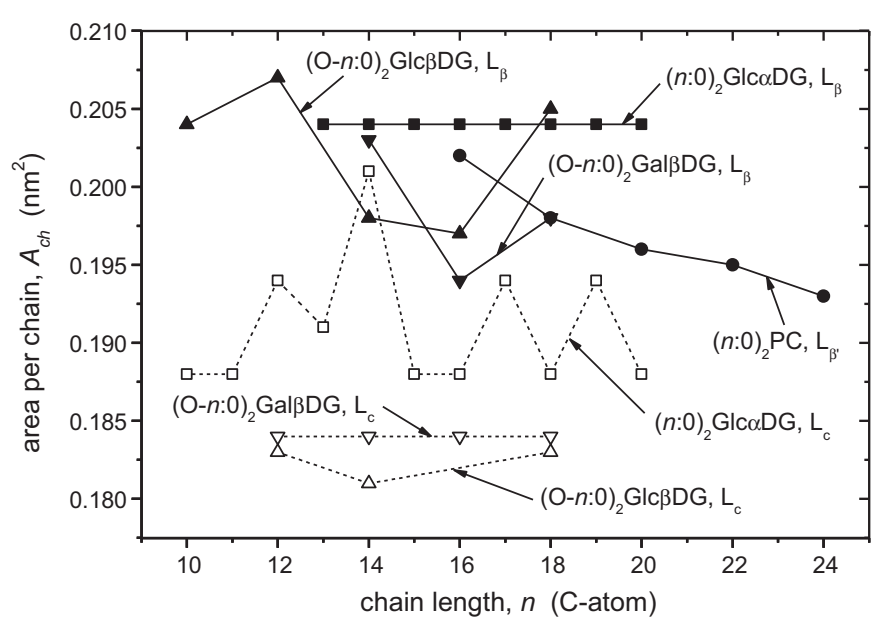

Fig. 3. Dependence of the area per chain, $A_{\mathrm{ch}}$, on lipid chain length, $n$, for 1,2-diacyl3- $\alpha$-D-glucosyl-sn-glycerols ( $(n: 0)_{2}$ Glc $\alpha$ DG, squares), 1,2-dialkyl-3- $\beta$-D-glucosylsn-glycerols ((O-n:0) $)_{2}$ Glc $\beta D G$, triangles), 1,2-dialkyl-3- $\beta$-D-galactosyl-sn-glycerols $\left((\mathrm{O}-n: 0)_{2}\right.$ GalßDG, inverted triangles) and 1,2-diacyl-sn-glycero-3-phosphocholines $\left((n: 0)_{2} \mathrm{PC}\right.$, circles $)$ in the lamellar gel $\left(L_{\beta}\right.$, solid symbols $)$ and crystalline lamellar $\left(L_{c}\right.$, open symbols) phases. Sources of the data for the different glycolipid series at $20^{\circ} \mathrm{C}$ are given in Table 1 , and for phosphatidylcholines at $25^{\circ} \mathrm{C}$ in Sun et al. (1996) (see also Marsh, 2011, 2012).

Because the chains in crystalline phases are in the all-trans configuration, information on chain tilt or area per lipid can be obtained from the dependence of the X-ray repeat spacing on lipid chain length. If the lipid hydration does not vary with chain length, the tilt angle, $\theta_{\mathrm{t}}$, is related to the increment, $d_{\mathrm{CH}_{2}}$, in repeat spacing per methylene group by:

$\cos \theta_{\mathrm{t}}=\frac{d_{\mathrm{CH}_{2}}}{d_{\mathrm{CH}_{2}}^{\mathrm{o}}}$

where $d_{\mathrm{CH}_{2}}^{\mathrm{O}}$ is the increment per methylene group along the chain direction, which has the value $d_{\mathrm{CH}_{2}}^{\mathrm{O}} \cong 0.127 \mathrm{~nm}$ (Smith, 1953) for a rigorously all-trans chain. Eq. (6) only can be applied usefully to analysing chain-length dependences of the long spacing if $d_{\mathrm{CH}_{2}}^{\mathrm{O}}$ is constant, which is a reasonable assumption for crystalline phases. This is not the case, however, for the gel phases of disaturated phosphatidylcholines, where the area per chain, $A_{\mathrm{ch}}$, varies systematically with lipid chain length (Tristram-Nagle et al., 1993; Sun et al., 1996). For the glycolipid gel phases that are considered here, measurements of $A_{\mathrm{ch}}$ do not display a systematic dependence on chain length (Sen et al., 1990; Köberl et al., 1998; Mannock et al., 2007), but the scatter is sometimes comparable to the systematic trends found with phosphatidylcholines (see Fig. 3). This point is considered further in Appendix A.

Additionally, the crystalline $L_{c}$ phases of glycolipids are often essentially anhydrous (Köberl et al., 1998), and it is then possible

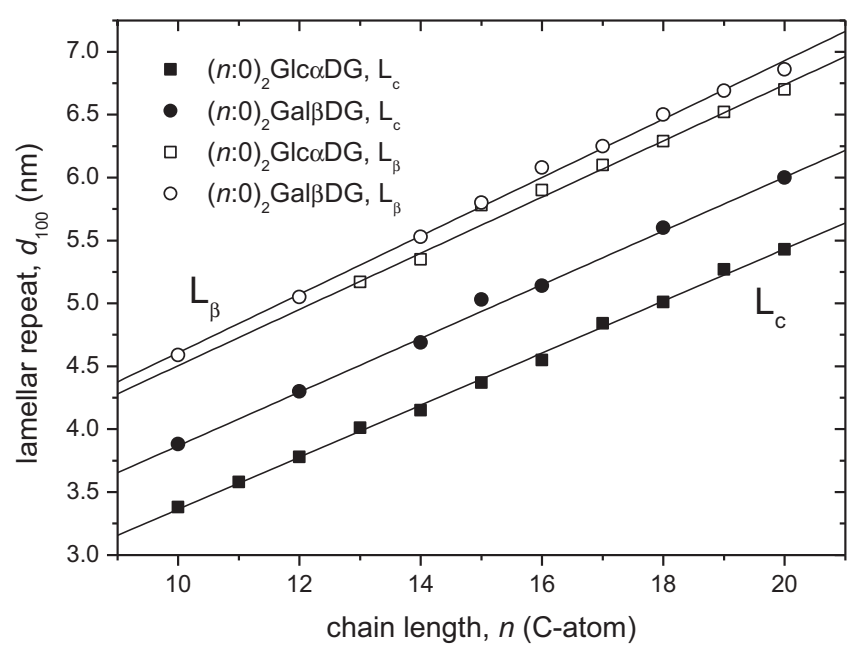

Fig. 4. Dependence of the lamellar repeat distance, $d_{100}$, on lipid chain length, $n$, for 1,2-diacyl-3- $\alpha$-D-glucosyl-sn-glycerols $\left((n: 0)_{2}\right.$ Glc $\alpha D G$, squares) and 1,2-diacyl3 - $\beta$-D-galactosyl-sn-glycerols $\left((n: 0)_{2}\right.$ Gal $\beta D G$, circles $)$ in the crystalline lamellar $\left(L_{c}\right.$, solid symbols) and lamellar gel ( $L_{\beta}$, open symbols) phases. Sources of the data for the different lipid series are given in Table 1.

to estimate the chain tilt from the repeat spacing at a single chain length, because $d_{\mathrm{w}} \approx 0$ and $d_{1} \approx d_{100}$.

\section{Chain-length dependence of lamellar repeat spacings}

Fig. 4 gives the chain-length dependence of the bilayer repeat spacing, $d_{100}$, for different series of glycosyl diacylglycerols dispersed in excess water, in the ordered - either crystalline $\left(L_{c}\right)$ or gel $\left(L_{\beta}\right)$ - phases. The long spacing depends approximately linearly on chain length for each glycolipid series at fixed temperature in a given phase. Table 1 lists the increments in repeat spacing, $d_{\mathrm{CH}_{2}}$, per methylene group that are obtained by linear regression with these, and also with dialkyl, lipid series. For the dialkyl glycosylglycerols, the increments are close to the value of $d_{\mathrm{CH}_{2}}^{\mathrm{o}}$ expected for an all-trans chain, indicating that the chains are essentially untilted in the ordered phases. As pointed out in the original publications, however, the increments for the diacyl monoglycosylglycerols are considerably smaller than expected for an all-trans chain. If Eq. (6) is applicable, this would imply a pronounced tilt of the chains $\left(\theta_{\mathrm{t}} \approx 30^{\circ}\right)$ in both $L_{\mathrm{c}}$ and $L_{\beta}$ phases of the glycoglycerolipids with ester-linked chains. The result is surprising for gel phases, because the same polar groups are involved as for the lipids with ether-linked chains, and the cross-sectional areas of these monohexoses are sufficiently small as not to exceed that of the two lipid chains. In addition, only a single sharp wide-angle reflection characteristic of the untilted $L_{\beta}$ structure is reported for the diacyl glucosylglycerol gel phases (Sen et al., 1990). Possibly the low values of $d_{\mathrm{CH}_{2}}$ for the diacyl glycolipid

Table 1

Increase in bilayer repeat distance per $\mathrm{CH}_{2}$ group, $d_{\mathrm{CH}_{2}}$, and effective chain tilt, $\theta_{t}$, for glycoglycerolipids in gel $\left(L_{\beta}\right)$ and crystalline $\left(L_{\mathrm{c}}\right)$ lamellar phases.

\begin{tabular}{|c|c|c|c|c|}
\hline Lipid & Phase & $d_{\mathrm{CH}_{2}}(\mathrm{~nm})$ & $\theta_{\mathrm{t}}\left({ }^{\circ}\right)^{\mathrm{a}}$ & Ref. \\
\hline \multirow[t]{2}{*}{$(0-n: 0)_{2}$ Glc $\beta D G$} & $L_{\mathrm{c}}$ & $0.122 \pm 0.007$ & $15 \pm 12$ & Köberl et al. (1998) \\
\hline & $L_{\beta}$ & $0.127 \pm 0.011$ & $0 \pm 24$ & Köberl et al. (1998) \\
\hline \multirow{3}{*}{$(\mathrm{O}-n: 0)_{2} \mathrm{Gal} \beta \mathrm{DG}$} & $L_{\mathrm{c} 1}$ & $0.121 \pm 0.004$ & $18 \pm 7$ & Mannock et al. (2007) \\
\hline & $L_{\mathrm{c} 2}$ & $0.124 \pm 0.007$ & $12 \pm 12$ & Mannock et al. (2007) \\
\hline & $L_{\beta}$ & $0.123 \pm 0.003$ & $14 \pm 6$ & Mannock et al. (2007) \\
\hline \multirow[t]{2}{*}{$(n: 0)_{2}$ Glc $\alpha$ DG } & $L_{\mathrm{c}}$ & $0.103 \pm 0.002$ & $35 \pm 1$ & Sen et al. (1990) \\
\hline & $L_{\beta}$ & $0.111 \pm 0.003$ & $28 \pm 3$ & Sen et al. (1990) \\
\hline \multirow[t]{2}{*}{$(n: 0)_{2} \mathrm{Gal} \beta \mathrm{DG}$} & $L_{\mathrm{c}}$ & $0.107 \pm 0.001$ & $33 \pm 1$ & Mannock et al. (2001) \\
\hline & $L_{\beta}$ & $0.116 \pm 0.003$ & $24 \pm 4$ & Mannock et al. (2001) \\
\hline
\end{tabular}

a Effective chain tilt, calculated from Eq. (6) with a fixed value of $d_{\mathrm{CH}_{2}}^{\mathrm{o}} \cong 0.127 \mathrm{~nm}$. Uncertainty ranges are those obtained from the linear regressions (see Fig. 1 ). 
Table 2

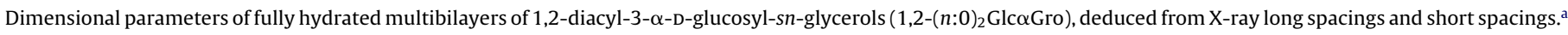

\begin{tabular}{|c|c|c|c|c|c|c|c|}
\hline Lipid & Phase & $T\left({ }^{\circ} \mathrm{C}\right)$ & $n_{\mathrm{w}, \max }(\mathrm{mol} / \mathrm{mol})$ & $d_{1}(\mathrm{~nm})$ & $d_{\mathrm{w}}(\mathrm{nm})$ & $A_{\mathrm{l}}\left(\mathrm{nm}^{2}\right)$ & $\theta_{\mathrm{t}}\left({ }^{\circ}\right)$ \\
\hline$(10: 0)_{2} \mathrm{Glc} \alpha \mathrm{DG}$ & $L_{\mathrm{c}}$ & 0 & 0 & 3.38 & 0 & 0.493 & 40 \\
\hline$(11: 0)_{2} \mathrm{Glc} \alpha \mathrm{DG}$ & $L_{\mathrm{c}}$ & 0 & 0 & 3.58 & 0 & 0.491 & 40 \\
\hline$(12: 0)_{2} \mathrm{Glc} \alpha \mathrm{DG}$ & $L_{\mathrm{c}}$ & 20 & 0 & 3.78 & 0 & 0.488 & 37 \\
\hline \multirow[t]{3}{*}{$(13: 0)_{2}$ Glc $\alpha$ DG } & $L_{\mathrm{c}}$ & 20 & 0 & 4.01 & 0 & 0.479 & 37 \\
\hline & $L_{\beta}$ & & 1.8 & 4.90 & 0.27 & 0.407 & 0 \\
\hline & & & (6.6 & 4.31 & 0.86 & 0.463 & 28) \\
\hline \multirow[t]{3}{*}{$(14: 0)_{2}$ Glc $\alpha$ DG } & $L_{\mathrm{c}}$ & 20 & 0 & 4.15 & 0 & 0.481 & 33 \\
\hline & $L_{\beta}$ & & 1.8 & 5.09 & 0.26 & 0.407 & 0 \\
\hline & & & $(6.7$ & 4.48 & 0.87 & 0.463 & 28) \\
\hline \multirow[t]{3}{*}{$(15: 0)_{2}$ Glc $\alpha$ DG } & $L_{\mathrm{c}}$ & 20 & 0 & 4.37 & 0 & 0.479 & 37 \\
\hline & $L_{\beta}$ & & 3.1 & 5.33 & 0.45 & 0.407 & 0 \\
\hline & & & $(8.4$ & 4.69 & 1.09 & 0.463 & 28) \\
\hline \multirow[t]{3}{*}{$(16: 0)_{2} \mathrm{Glc} \alpha \mathrm{DG}$} & $L_{\mathrm{c}}$ & 20 & 0 & 4.55 & 0 & 0.481 & 39 \\
\hline & $L_{\beta}$ & & 2.2 & 5.57 & 0.33 & 0.407 & 0 \\
\hline & & & $(7.7$ & 4.90 & 1.00 & 0.463 & 28) \\
\hline \multirow[t]{3}{*}{$(17: 0)_{2} \mathrm{Glc} \alpha \mathrm{DG}$} & $L_{\mathrm{c}}$ & 20 & 0 & 4.84 & 0 & 0.467 & 34 \\
\hline & $L_{\beta}$ & & 2.1 & 5.79 & 0.31 & 0.407 & 0 \\
\hline & & & $(7.8$ & 5.09 & 1.01 & 0.463 & 28) \\
\hline \multirow{3}{*}{$(18: 0)_{2} \mathrm{Glc} \alpha \mathrm{DG}$} & $L_{\mathrm{c}}$ & 20 & 0 & 5.01 & 0 & 0.466 & 36 \\
\hline & $L_{\beta}$ & & 1.8 & 6.02 & 0.28 & 0.407 & 0 \\
\hline & & & (7.7 & 5.29 & 1.00 & 0.463 & 28) \\
\hline \multirow[t]{3}{*}{$(19: 0)_{2} \mathrm{Glc} \alpha \mathrm{DG}$} & $L_{\mathrm{c}}$ & 20 & 0 & 5.27 & 0 & 0.459 & 32 \\
\hline & $L_{\beta}$ & & 2.0 & 6.22 & 0.30 & 0.407 & 0 \\
\hline & & & (8.1 & 5.47 & 1.05 & 0.463 & 28) \\
\hline \multirow[t]{3}{*}{$(20: 0)_{2}$ Glc $\alpha$ DG } & $L_{\mathrm{c}}$ & 20 & 0 & 5.43 & 0 & 0.461 & 35 \\
\hline & $L_{\beta}$ & & 1.8 & 6.43 & 0.27 & 0.407 & 0 \\
\hline & & & (8.0 & 5.66 & 1.04 & 0.463 & 28) \\
\hline
\end{tabular}

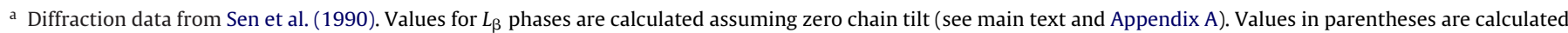
assuming the effective chain tilts for $L_{\beta}$ phases obtained from the chain length dependence of the long spacing (Table 1 ).

gel phases are attributable to systematic changes in $A_{\mathrm{ch}}$ with chain length, as for phosphatidylcholines, even though no trend is evident to within the reported precision of the wide-angle spacings for $(n: 0)_{2}$ Glc $\alpha$ DG $L_{\beta}$ phases (see Fig. 3). Such reservations do not apply, however, to the crystalline $L_{\mathrm{c}}$ phases, where the chains are truly all-trans. Unlike the gel phases, both tilted and non-tilted crystalline polymorphs are known for lipids with small polar groups, such as phosphatidylethanolamines (Seddon et al., 1983).

\section{From lipid areas and repeat spacings to bilayer thickness and lipid hydration}

In principle, the chain tilt angles in Table 1 can be combined with the area per chain, $A_{\mathrm{ch}}$, obtained from the wide-angle X-ray spacings (see, e.g., Marsh, 2011, 2012 and Fig. 3), to give the area per lipid, $A_{\mathrm{l}}$, at the bilayer surface by using Eq. (5). Combining this with the volume per lipid molecule, $v_{1}$, obtained from densitometry (see, e.g., Marsh, 2010), then yields the bilayer thickness, $d_{1}$, by using Eq. (2). The water-layer thickness, $d_{\mathrm{w}}$, is then obtained directly from $d_{1}$ and the measured lamellar repeat distance, $d_{100}$, by using Eq. (4). Finally, the degree of lipid hydration ( $n_{\mathrm{w}, \max }$ waters per lipid) is obtained from Eq. (3), by using once more the lipid molecular volume, $v_{1}$. Note that the molecular volume of water is $v_{\mathrm{w}}=0.030 \mathrm{~nm}^{3}$. The value obtained for $n_{\mathrm{w}, \max }$ in this way is independent of any assumptions about the relative distribution of water and lipid, because Eq. (3) simply represents additivity of the total volumes of the water and lipid components, as embodied in Eq. (1).

Application of this method to glycolipid $L_{\mathrm{c}}$ phases indicates that the crystalline states are essentially anhydrous. In this case, the method can be reversed by using the condition $n_{\mathrm{w} \text {,max }} \approx 0$ (i.e., $d_{1} \approx d_{100}$ ) to calculate the tilt angle, $\theta_{\mathrm{t}}$, for individual chain lengths, instead of assuming an average tilt for all chain lengths as is done from the linear regression results in Table 1.
As already mentioned, a further alternative exists for untilted chains because these may be identified for a single lipid species from the single, sharp chain reflection in the wide-angle region, which is a diagnostic feature of the untilted $L_{\beta}$ phase (see, e.g., McIntosh, 1980). In this case, it can be assumed that $\theta_{\mathrm{t}}=0$ without recourse to the chain-length dependence of the long spacing.

\section{1,2-Diacyl-3- $\alpha$-D-glucosyl-sn-glycerols}

Small-angle and wide-angle X-ray data for the 1,2$(n: 0)_{2}$ Glc $\alpha$ Gro homologous series of glucosyl diacylglycerols in excess water were obtained by Sen et al. (1990). A single sharp reflection that is characteristic of nontilted, hexagonally packed chains is found in the wide-angle region from bilayers in the $L_{\beta}$ gel phase (cf. Tardieu et al., 1973; McIntosh, 1980). Thus, in spite of the results from the chain-length dependence of the long spacing (discussed above in Section 3), a value of $\theta_{\mathrm{t}}=0$ is used to calculate the bilayer thickness and lipid hydration for the $L_{\beta}$-phase in Table 2. (For comparison, corresponding values that are obtained by assuming a tilt of $\theta_{\mathrm{t}}=28^{\circ}$ from Table 1 are given in parentheses.) Partial support for assuming that the chains are almost untilted in the gel phase is given in Appendix A.

The number of waters per lipid does not show any systematic trend with chain length, $n$, for the $L_{\beta}$ phase of the $(n: 0)_{2}$ Glc $\alpha$ DG series. At full hydration, the mean number of waters per lipid that is calculated by assuming that the chains are not tilted is $n_{\mathrm{w}, \max }=2.1 \pm 0.4 \mathrm{~mol} / \mathrm{mol}$. (For a tilt of $28^{\circ}$ the number calculated is correspondingly larger: $n_{\mathrm{w}, \max }=7.6 \pm 0.6 \mathrm{~mol} / \mathrm{mol}$.)

From the chain-length dependence of the long spacing, the mean tilt angle of the chains in the crystalline $L_{\mathrm{c}}$ phase is $35^{\circ}$ (see Table 1). A calculation of the number of waters per lipid on this basis reveals that $n_{\mathrm{w}, \max } \approx 0$ for the crystalline $L_{\mathrm{c}}$ phase, and therefore the condition $n_{\mathrm{w}, \max }=0$ is assumed to calculate tilt angles for the individual chain lengths in Table 2 . The individual tilt angles are all 
Table 3

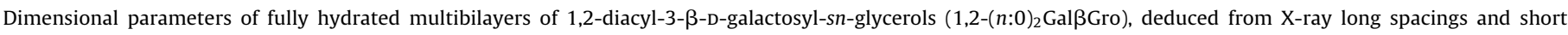
spacings. ${ }^{a}$

\begin{tabular}{|c|c|c|c|c|c|c|c|}
\hline Lipid & Phase & $T\left({ }^{\circ} \mathrm{C}\right)$ & $n_{\mathrm{w}, \max }(\mathrm{mol} / \mathrm{mol})$ & $d_{1}(\mathrm{~nm})$ & $d_{\mathrm{w}}(\mathrm{nm})$ & $A_{1}\left(\mathrm{~nm}^{2}\right)$ & $\theta_{\mathrm{t}}\left({ }^{\circ}\right)$ \\
\hline \multirow[t]{3}{*}{$(10: 0)_{2}$ Gal $\beta D G$} & $L_{\mathrm{c}}$ & 48.5 & 1.1 & 3.73 & 0.15 & 0.447 & 33 \\
\hline & $L_{\beta}$ & -6.8 & 3.6 & 4.05 & 0.54 & 0.407 & 0 \\
\hline & & & $(6.6$ & 3.71 & 0.88 & 0.445 & 24) \\
\hline \multirow[t]{3}{*}{$(12: 0){ }_{2} \mathrm{Gal} \beta \mathrm{DG}$} & $L_{\mathrm{c}}$ & 63.5 & 1.3 & 4.12 & 0.18 & 0.447 & 33 \\
\hline & $L_{\beta}$ & 23.1 & 2.4 & 4.70 & 0.35 & 0.407 & 0 \\
\hline & & & $(5.6$ & 4.30 & 0.75 & 0.445 & 24) \\
\hline \multirow[t]{3}{*}{$(14: 0){ }_{2} \mathrm{Gal} \beta \mathrm{DG}$} & $L_{\mathrm{c}}$ & 68.7 & 1.7 & 4.46 & 0.23 & 0.447 & 33 \\
\hline & $L_{\beta}$ & 44.2 & 3.0 & 5.09 & 0.44 & 0.407 & 0 \\
\hline & & & $(6.5$ & 4.65 & 0.88 & 0.445 & 24) \\
\hline \multirow[t]{3}{*}{$(15: 0)_{2}$ Gal $\beta D G$} & $L_{\mathrm{c}}$ & 75 & 2.6 & 4.68 & 0.35 & 0.447 & 33 \\
\hline & $L_{\beta}$ & 54 & 3.2 & 5.33 & 0.47 & 0.407 & 0 \\
\hline & & & $(6.9$ & 4.87 & 0.93 & 0.445 & 24) \\
\hline \multirow[t]{3}{*}{$(16: 0)_{2}$ Gal $\beta D G$} & $\mathrm{~L}_{\mathrm{c}}$ & 76.7 & 1.9 & 4.89 & 0.25 & 0.447 & 33 \\
\hline & $L_{\beta}$ & 59.5 & 3.4 & 5.57 & 0.51 & 0.407 & 0 \\
\hline & & & (7.3 & 5.09 & 0.99 & 0.445 & 24) \\
\hline \multirow[t]{2}{*}{$(17: 0)_{2}$ Gal $\beta D G$} & $L_{\beta}$ & 64 & 3.1 & 5.79 & 0.46 & 0.407 & 0 \\
\hline & & & $(7.1$ & 5.29 & 0.96 & 0.445 & 24) \\
\hline \multirow[t]{3}{*}{$(18: 0)_{2} \mathrm{Gal} \beta \mathrm{DG}$} & $L_{\mathrm{c}}$ & 81.7 & 2.8 & 5.22 & 0.38 & 0.447 & 33 \\
\hline & $L_{\beta}$ & 66.5 & 3.3 & 6.02 & 0.48 & 0.407 & 0 \\
\hline & & & $(7.4$ & 5.50 & 1.00 & 0.445 & 24) \\
\hline \multirow[t]{2}{*}{$(19: 0){ }_{2}$ Gal $\beta D G$} & $L_{\beta^{\prime}}$ & 66 & 3.2 & 6.22 & 0.47 & 0.407 & 0 \\
\hline & & & $(7.4$ & 5.69 & 1.00 & 0.445 & 24) \\
\hline \multirow[t]{3}{*}{$(20: 0){ }_{2}$ Gal $\beta D G$} & $L_{\mathrm{c}}$ & 25 & 3.1 & 5.59 & 0.41 & 0.447 & 33 \\
\hline & $L_{\beta}$ & 71.5 & 2.9 & 6.43 & 0.43 & 0.407 & 0 \\
\hline & & & $(7.3$ & 5.88 & 0.98 & 0.445 & 24) \\
\hline
\end{tabular}

a Diffraction data from Mannock et al. (2001). Values for $L_{\beta}$ phases are calculated assuming zero chain tilt (see main text and Appendix A). Values in parentheses are calculated assuming the effective chain tilts for $L_{\beta}$ phases obtained from the chain length dependence of the long spacing (Table 1 ).

reasonably close to the mean tilt angle of $\theta_{\mathrm{t}}=35 \pm 1^{\circ}$ that is given for the $L_{c}$ phase of this series in Table 1 .

Because partial specific volumes, $\bar{v}_{1}$, are not available for this series of lipids, these are assumed to be equal to those for the corresponding (O- $n: 0)_{2}$ Glc $\beta D G s$ (Hinz et al., 1991) in calculating the molecular volumes $\left(v_{1}=M_{1} \bar{v}_{1} / N_{\mathrm{A}}\right)$. Note that, to within the reported precision of the short spacings, the area per chain, $A_{\mathrm{ch}}$, of the $(n: 0)_{2}$ Glc $\alpha$ DGs does not vary with chain length, $n$ (see Fig. 3 ).

\section{1,2-Diacyl-3- $\beta$-D-galactosyl-sn-glycerols}

Only low-angle diffraction data are available for the 1,2( $n: 0)_{2}$ GalßGro homologous series (Mannock et al., 2001). Because the increments in long spacing, $d_{\mathrm{CH}_{2}}$, are similar to those for the 1,2-(n:0) ${ }_{2}$ Glc $\alpha$ Gro series (see Table 1 ), it can be assumed that the chain cross-sectional areas are also similar. Therefore, a value of $A_{\mathrm{ch}}=0.204 \mathrm{~nm}^{2}$ is taken for the chain cross-sectional area in the $L_{\beta}$ phase, and a value of $A_{\mathrm{ch}}=0.188 \mathrm{~nm}^{2}$ in the $L_{\mathrm{c}}$ phase. Table 3 gives the hydration levels of the $L_{\beta}$ phases that are calculated in the same way as for those of the $(n: 0)_{2}$ Glc $\alpha$ DG series in Table 2 . Again, the partial specific volumes of the (O- $n: 0)_{2}$ Glc $\beta D G$ series (Hinz et al., $1991)$ are used in calculating the molecular volumes.

The hydration levels calculated for the $L_{\beta}$ phase of the galactosyl diacylglycerols are comparable to those of the corresponding glucosyl diacylglycerols. The mean number of waters per lipid at full hydration is found to be: $n_{\mathrm{w}, \max }=3.1 \pm 0.3 \mathrm{~mol} / \mathrm{mol}$, assuming that the chains are not tilted. $\left(n_{\mathrm{w}, \max }=6.9 \pm 0.6 \mathrm{~mol} / \mathrm{mol}\right.$, if a tilt of $24^{\circ}$ is assumed from Table 1.) A small, but non-zero, level of hydration is calculated for the $L_{\mathrm{c}}$ phases of the galactosyl diacylglycerols if the mean tilt angle of $\theta_{\mathrm{t}}=33 \pm 1^{\circ}$ is taken from Table 1 . If alternatively it is assumed that the $L_{\mathrm{c}}$ phase is not hydrated, as is done for the glucosyl diacylglycerols in Table 2, then the individual chain tilt angles that are calculated for the galactosyl diacylglycerols lie in the range $25^{\circ}-29^{\circ}$, which is somewhat less than the mean value that is deduced from the chain-length dependence of the long spacing in Table 1.

\section{Dialkyl- $\beta$-D-monoglycosyl-glycerols}

Table 4 summarises collected data for the $L_{c}$ and $L_{\beta}$ phases of 1,2-dialkyl-3- $\beta$-D-glucosyl-sn-glycerols, $\quad 1,2$-dialkyl-3- $\beta$-Dgalactosyl-sn-glycerols, 1,2 -dialkyl-3- $\beta$-D-mannosyl-sn-glycerols, 2,3-dialkyl-1- $\beta$-D-galactosyl-sn-glycerol, dialkyl- $\beta$-D-glucosylrac-glycerols and dialkyl- $\beta$-D-galactosyl-rac-glycerols. Where a value of the cross-sectional area per chain, $A_{\mathrm{ch}}$, is not available for the $L_{c}$ phases, it is assumed to be the same as that for $n$-alkanes: $A_{\mathrm{ch}}=0.182 \mathrm{~nm}^{2}$ (see Köberl et al., 1998).

For the $L_{c}$ phases of $(0-10: 0)_{2-},(0-12: 0)_{2^{-}}$and $(0-$ 16:0 $)_{2}$ Glc $\beta$ DG, and of $(0-16: 0)_{2}-$ and $(0-18: 0)_{2}$ Gal $\beta D G$, it is assumed that the crystalline phase is not hydrated $\left(n_{\mathrm{w}, \max } \approx 0\right)$. The resulting chain tilt angles are nonzero, but small and similar, which is consistent with the chain-length dependence of $d_{100}$ (see Table 1). Conversely, it is assumed from Table 1 that the chain tilt angle is zero $\left(\theta_{\mathrm{t}} \approx 0\right)$ for the $L_{\beta}$ phases, and also for the $L_{\mathrm{c}}$ phases, of (O-10:0 $)_{2}$ - and (O-14:0 $)_{2}$ Gal $\beta D G$, and of $(0-14: 0)_{2}$ - and $(\mathrm{O}-18: 0)_{2} \mathrm{Glc} \beta D G$. The resulting degrees of hydration, represented by $d_{\mathrm{w}}$ and $n_{\mathrm{w}}$, are relatively small for the $L_{\beta}$ phases and essentially zero for the $L_{c}$ phases. Gravimetric determinations of the degree of hydration $\left(n_{\mathrm{w}, \max }=6.3\right.$ and $\left.7 \mathrm{~mol} / \mathrm{mol}\right)$ for the $L_{\beta}$ gel phases of $(0-12: 0)_{2}$ - and (O-14:0 $)_{2}$ Glc $\beta D G$ (Turner et al., 1992; Seddon et al., 2003) lead to tilt angles of $\theta_{t}=19^{\circ}$ and $23^{\circ}$, which are somewhat greater than the mean value of $\theta_{t}=0 \pm 23^{\circ}$ deduced from the chain-length dependence of the (O- $n: 0)_{2}$ Glc $\beta D G$ series in Table 1 , but lie within the uncertainty range. As already noted, gravimetric methods tend to overestimate $n_{\mathrm{w} \text {,max }}$, if part of the water is incorporated in defect regions outside the regular multilamellae (Koenig et al., 1997; Nagle and Tristram-Nagle, 2000).

Taken collectively, the data for the 1,2-dialkyl glycosylglycerols are consistent with close to no chain tilt for the $L_{c}$ and $L_{\beta}$ phases, essentially dehydrated $L_{c}$ phases, and low degrees of hydration for the $L_{\beta}$ phases (mean value $n_{\mathrm{w}, \max } \approx 4.3 \pm 1.5 \mathrm{~mol} / \mathrm{mol}$ ), in both glucosyl and galactosyl glycerolipid series. This applies also for the 2,3-dialkyl galactosyl species in Table 4. In general, the degree of hydration of the $L_{\beta}$ phases of the dialkyl glycosyl glycerols appears 
Table 4

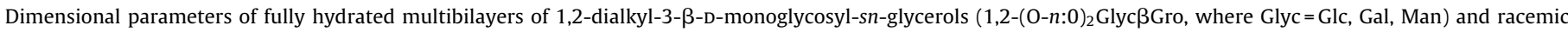
mixtures (rac-(O-n:0) $)_{2}$ Gal $\left.\beta D G\right)$, deduced from X-ray long spacings and short spacings.

\begin{tabular}{|c|c|c|c|c|c|c|c|c|}
\hline Lipid & Phase & $T\left({ }^{\circ} \mathrm{C}\right)$ & $n_{\mathrm{w}, \max }(\mathrm{mol} / \mathrm{mol})$ & $d_{1}(\mathrm{~nm})$ & $d_{\mathrm{w}}(\mathrm{nm})$ & $A_{\mathrm{l}}\left(\mathrm{nm}^{2}\right)$ & $\theta_{\mathrm{t}}\left(^{\circ}\right)$ & Ref. \\
\hline \multirow[t]{2}{*}{$(0-10: 0)_{2}$ Glc $\beta D G$} & $L_{\mathrm{c}}$ & 20 & 0 & 4.25 & 0 & 0.373 & 12 & Köberl et al. (1998) \\
\hline & $L_{\beta}$ & 20 & 3.0 & 3.91 & 0.44 & 0.408 & 0 & Köberl et al. (1998) \\
\hline$(0-10: 0)_{2}$ Gal $\beta D G$ & $L_{\mathrm{c}}$ & 20 & 0.3 & 4.30 & 0.05 & 0.368 & 0 & Köberl et al. (1998) \\
\hline \multirow[t]{2}{*}{$(0-12: 0)_{2}$ Glc $\beta D G$} & $L_{\mathrm{c}}$ & 20 & 0 & 4.74 & 0 & 0.371 & 10 & Köberl et al. (1998) \\
\hline & $L_{\beta}$ & 20 & 5.2 & 4.41 & 0.76 & 0.414 & 0 & Köberl et al. (1998) \\
\hline rac- $(0-12: 0)_{2}$ Glc $\beta D G$ & $L_{\beta}$ & 30 & 6.4 & 4.21 & 0.88 & 0.437 & $19^{\mathrm{a}}$ & Turner et al. (1992) \\
\hline \multirow[t]{6}{*}{$(0-14: 0)_{2}$ Glc $\beta$ DG } & $L_{\mathrm{c}}$ & 20 & 1.2 & 5.33 & 0.21 & 0.359 & 0 & Hinz et al. (1991) \\
\hline & & & 2.8 & 4.83 & 0.42 & 0.396 & 0 & Seddon et al. (2003) \\
\hline & & 30 & 5.0 & 4.94 & 0.74 & 0.406 & 0 & Hinz et al. (1991) \\
\hline & & 46 & 0.0 & 5.41 & 0.01 & 0.362 & 0 & Köberl et al. (1998) \\
\hline & $L_{\beta}$ & 20 & 4.9 & 5.01 & 0.74 & 0.396 & 0 & Köberl et al. (1998) \\
\hline & & & $7^{\mathrm{b}}$ & 4.60 & 0.97 & 0.432 & 23 & Seddon et al. (2003) \\
\hline \multirow{3}{*}{$(0-14: 0)_{2}$ Gal $\beta D G$} & $L_{\mathrm{c}}$ & 20 & 0.7 & 5.38 & 0.11 & 0.368 & 0 & Hinz et al. (1991) \\
\hline & $L_{\mathrm{c} 1}$ & & 0.1 & 5.39 & 0.01 & 0.368 & 0 & Seddon et al. (2003) \\
\hline & $L_{\beta}$ & 30 & 3.5 & 4.98 & 0.51 & 0.406 & 0 & Hinz et al. (1991) \\
\hline \multirow[t]{3}{*}{$\operatorname{rac}-(\mathrm{O}-14: 0)_{2} \mathrm{Gal} \beta \mathrm{DG}$} & $\mathrm{L}_{\mathrm{c} 1}$ & 20 & 0 & 5.34 & 0 & 0.371 & 18 & Mannock et al. (2007) \\
\hline & $L_{\mathrm{c} 2}$ & 55 & 0.6 & 5.14 & 0.09 & 0.387 & 12 & Mannock et al. (2007) \\
\hline & $L_{\beta}$ & 20 & 5.6 & 4.84 & 0.81 & 0.410 & 14 & Mannock et al. (2007) \\
\hline \multirow[t]{2}{*}{$2,3-(\mathrm{O}-14: 0)_{2} \mathrm{Gal} \beta \mathrm{DG}^{\mathrm{c}}$} & $L_{\mathrm{c}}$ & 20 & 0.7 & 5.38 & 0.12 & 0.368 & 0 & Kuttenreich et al. (1993) \\
\hline & $L_{\beta}$ & 50 & 3.0 & 5.05 & 0.45 & 0.404 & 0 & Kuttenreich et al. (1993) \\
\hline \multirow[t]{2}{*}{ rac- $(0-15: 0)_{2}$ Gal $\beta D G$} & $\mathrm{~L}_{\mathrm{c} 1}$ & 1 & 0 & 5.49 & 0 & 0.380 & 19 & Mannock et al. (2007) \\
\hline & $L_{\beta}$ & 11 & 5.4 & 5.07 & 0.79 & 0.408 & 14 & Mannock et al. (2007) \\
\hline \multirow[t]{2}{*}{$(0-16: 0)_{2}$ Glc $\beta D G$} & $L_{\mathrm{c}}$ & 20 & 0 & 5.60 & 0 & 0.372 & 11 & Tenchova et al. (1996) \\
\hline & $L_{\beta}$ & 20 & 5.6 & 5.48 & 0.86 & 0.394 & 0 & Köberl et al. (1998) \\
\hline \multirow[t]{2}{*}{$(0-16: 0)_{2}$ Gal $\beta D G$} & $L_{\mathrm{c}}$ & 20 & 0 & 6.10 & 0 & 0.398 & 22 & Köberl et al. (1998), Hinz et al. (1991) \\
\hline & $L_{\beta}$ & 20 & 1.2 & 6.09 & 0.19 & 0.388 & 0 & Köberl et al. (1998), Hinz et al. (1991) \\
\hline \multirow[t]{2}{*}{ rac- $(0-16: 0)_{2}$ Gal $\beta D G$} & $L_{c}$ & 1 & 0 & 5.79 & 0 & 0.379 & 25 & Mannock et al. (2007) \\
\hline & $L_{\beta}$ & 11 & 4.2 & 5.49 & 0.65 & 0.390 & 14 & Mannock et al. (2007) \\
\hline$(0-16: 0)_{2} \operatorname{Man} \beta D G$ & $L_{\beta}$ & 30 & 4.2 & 5.66 & 0.66 & 0.384 & 0 & Hinz et al. (1991) \\
\hline \multirow[t]{4}{*}{$(0-18: 0)_{2}$ Glc $\beta D G$} & $L_{\mathrm{c}}$ & 20 & 0.3 & 6.15 & 0.05 & 0.366 & 0 & Hinz et al. (1991) \\
\hline & & & 0.7 & 6.27 & 0.12 & 0.366 & 0 & Köberl et al. (1998) \\
\hline & $L_{\beta}$ & 20 & 6.2 & 5.76 & 0.91 & 0.410 & 0 & Köberl et al. (1998) \\
\hline & & 60 & 4.6 & 6.03 & 0.69 & 0.404 & 0 & Hinz et al. (1991) \\
\hline \multirow[t]{2}{*}{$(0-18: 0)_{2}$ Gal $\beta D G$} & $L_{\mathrm{c}}$ & 20 & 0 & 6.70 & 0 & 0.363 & 9 & Hinz et al. (1991) \\
\hline & $L_{\beta}$ & 20 & 4.8 & 5.97 & 0.73 & 0.396 & 0 & Hinz et al. (1991) \\
\hline rac- $(\mathrm{O}-18: 0)_{2}$ Gal $\beta D G$ & $L_{\beta}$ & 40 & 5.0 & 5.86 & 0.74 & 0.400 & 14 & Mannock et al. (2007) \\
\hline
\end{tabular}

a Calculated assuming $A_{\mathrm{ch}}=0.212 \mathrm{~nm}^{2}$ (Köberl et al., 1998); $n_{\mathrm{w}, \max }$ is determined from the hydration dependence in Fig. 2 .

b Determined from the hydration dependence (Seddon et al., 2003).

c $s n-1$ stereoisomer. Unless specifically stated otherwise, the $s n-3$ stereoisomer is normally assumed.

to be comparable to that of the $L_{\beta}$ phases of the diacyl glycosylglycerols, assuming that the latter are also untilted (compare Table 4 with Tables 2 and 3).

Data for the lipid series with racemic glycerol backbone, rac$(0-n: 0)_{2}$ Gal $\beta D G$, are also given in Table 4 . Here, the crystalline $L_{\mathrm{c}}$ phases are assumed to be completely dehydrated $\left(n_{\mathrm{w}, \max }=0\right)$, and the $L_{\beta}$ gel phases are taken to have a small tilt of $\theta_{\mathrm{t}}=14^{\circ}$ from Table 1. Partial specific volumes for the racemic mixtures are taken to be approximately the same as for the corresponding 1,2-(O- $n: 0)_{2}$ Gal $\beta D G$ or $1,2-(0-n: 0)_{2}$ Glc $\beta D G$ lipids (Hinz et al., 1991). The resulting tilt angles for the $L_{\mathrm{c}}$ phases are all small, and close to the mean value for the different chain lengths that is given in Table 1 . The degrees of hydration that are deduced for the $L_{\beta}$ phases of the rac-dialkyl galactosylglycerols (mean value $n_{\mathrm{w}, \max }=5.0 \pm 0.6 \mathrm{~mol} / \mathrm{mol}$ ) are mostly similar to those for the corresponding 1,2-enantiomer.

\section{1,2-Dialkyl-3- $\beta$-D-diosyl, -triosyl and -oligolactosyl-sn-glycerols}

Table 5 presents data for the $L_{c}$ and $L_{\beta}$ phases of dialkyl glycosylglycerols with polar groups that have higher degrees of glycosylation, from two up to six hexose units (viz., $\mathrm{Lac}_{3}$ ). For the oligolactose dialkylglycerols, (0-16:0 $)_{2} \mathrm{Lac}_{m} \beta \mathrm{BG}$, the molecular volumes are based on (0-16:0) 2 MalßDG (Köberl et al., 1998), with $0.192 \mathrm{~nm}^{3}$ (Marsh, 2010) for each further hexose unit.

It is assumed that the $L_{\mathrm{c}}$ phases are essentially dehydrated $\left(n_{\mathrm{w}, \max } \approx 0\right)$, and the resulting chain tilts for $(0-16: 0)_{2} \mathrm{Lac} \beta \mathrm{DG}$ and

Table 5

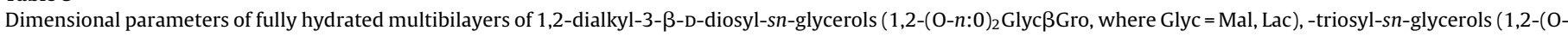
$\left.n: 0)_{2} \mathrm{Mtr} \beta \mathrm{Gro}\right)$, and -oligolactosyl-sn-glycerols (1,2-(O-n:0)$\left.)_{2} \mathrm{Lac} \beta_{m} \mathrm{Gro}\right)$, deduced from X-ray long spacings and short spacings.

\begin{tabular}{|c|c|c|c|c|c|c|c|c|}
\hline Lipid $^{\mathrm{a}}$ & Phase & $T\left({ }^{\circ} \mathrm{C}\right)$ & $n_{\mathrm{w}, \max }(\mathrm{mol} / \mathrm{mol})$ & $d_{1}(\mathrm{~nm})$ & $d_{\mathrm{w}}(\mathrm{nm})$ & $A_{1}\left(\mathrm{~nm}^{2}\right)$ & $\theta_{\mathrm{t}}\left({ }^{\circ}\right)$ & Ref. \\
\hline$(0-14: 0)_{2} \mathrm{Mal} \beta D G$ & $L_{\beta}$ & 20 & 2.1 & 6.24 & 0.32 & 0.388 & 0 & Hinz et al. (1991) \\
\hline$(0-16: 0)_{2}$ Mal $\beta D G$ & $L_{\beta}$ & 20 & 2.9 & 6.74 & 0.46 & 0.382 & 0 & Hinz et al. (1991) \\
\hline \multirow[t]{2}{*}{$(0-16: 0)_{2}$ Lac $\beta D G$} & $L_{\mathrm{c}}$ & 20 & 0 & 6.71 & 0 & 0.384 & 10 & Köberl et al. (1998) \\
\hline & & & 0 & 6.80 & 0 & 0.379 & 12 & Schneider et al. (2003) \\
\hline$(0-16: 0)_{2} \operatorname{Lac} \beta_{2}$ DG & $L_{\beta}$ & 20 & 2.6 & 8.31 & 0.39 & 0.402 & 0 & Schneider et al. (2003) \\
\hline$(0-16: 0)_{2} \mathrm{Lac}_{3} \mathrm{DG}$ & $L_{\mathrm{c}}$ & 20 & 0 & 11.10 & 0 & 0.370 & 11 & Schneider et al. (2003) \\
\hline$(0-18: 0)_{2} M \operatorname{tr} \beta D G$ & $L_{\beta}$ & 20 & 5.0 & 7.32 & 0.75 & 0.398 & 0 & Hinz et al. (1991) \\
\hline
\end{tabular}

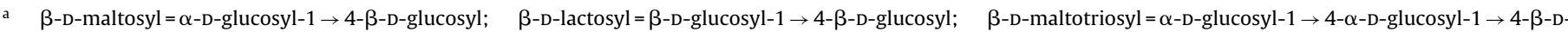
glucosyl; Lac $\beta_{3}=3-\beta$-D-lactosyl- $\rightarrow 3-\beta$-D-lactosyl- $\rightarrow 3-\beta$-D-lactosyl. 
Table 6

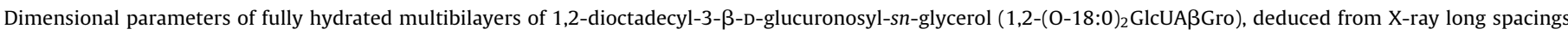
and short spacings. ${ }^{a}$

\begin{tabular}{|c|c|c|c|c|c|c|c|}
\hline $\mathrm{pH}$ & Phase & $T\left({ }^{\circ} \mathrm{C}\right)$ & $n_{\mathrm{w}, \max }(\mathrm{mol} / \mathrm{mol})$ & $d_{1}(\mathrm{~nm})$ & $d_{\mathrm{w}}(\mathrm{nm})$ & $A_{1}\left(\mathrm{~nm}^{2}\right)$ & $\theta_{\mathrm{t}}\left(^{\circ}\right)$ \\
\hline \multirow[t]{3}{*}{1.6} & $L_{\beta}$ & 20 & 5.4 & 5.85 & 0.85 & 0.380 & 0 \\
\hline & & 40 & 5.4 & 5.86 & 0.84 & 0.386 & 0 \\
\hline & & 60 & 5.5 & 5.81 & 0.82 & 0.398 & 0 \\
\hline 10 & $L_{\beta}$ & 20 & 6.8 & 5.94 & 1.03 & 0.394 & 0 \\
\hline
\end{tabular}

a Data from Koynova et al. (1993).

Table 7

Dimensional parameters of fully hydrated multibilayers of glycosphingolipids, deduced from X-ray long spacings and short spacings.

\begin{tabular}{|c|c|c|c|c|c|c|c|c|}
\hline Lipid & Phase & $T\left({ }^{\circ} \mathrm{C}\right)$ & $n_{\mathrm{w}, \max }(\mathrm{mol} / \mathrm{mol})$ & $d_{1}(\mathrm{~nm})$ & $d_{\mathrm{w}}(\mathrm{nm})$ & $A_{\mathrm{l}}\left(\mathrm{nm}^{2}\right)$ & $\theta_{\mathrm{t}}\left({ }^{\circ}\right)$ & Ref. \\
\hline \multirow[t]{2}{*}{ GlcCer(d18:1/16:0) } & $L_{\mathrm{c} 1}$ & 20 & 0 & 5.23 & 0 & 0.431 & 23 & Saxena et al. (1999) \\
\hline & $L_{\mathrm{c} 2}$ & 70 & 0 & 5.39 & 0 & 0.418 & 15 & Saxena et al. (1999) \\
\hline \multirow[t]{2}{*}{ GalCer(d18:1/16:0) } & $L_{\mathrm{c} 1}$ & 20 & 0 & 5.67 & 0 & 0.398 & 11 & Saxena et al. (1999) \\
\hline & $L_{\mathrm{c} 2}$ & 70 & 0 & 5.52 & 0 & 0.409 & 17 & Saxena et al. (1999) \\
\hline \multirow[t]{2}{*}{ GalCer(d18:1/18:0) } & $L_{\mathrm{c} 1}$ & 21 & 0 & 5.96 & 0 & 0.394 & 14 & Reed and Shipley (1989) \\
\hline & $L_{\mathrm{c} 2}$ & 61 & 0 & 5.84 & 0 & 0.402 & 18 & Reed and Shipley (1989) \\
\hline \multirow[t]{2}{*}{ GalCer(d18:1/24:0) } & $L_{\mathrm{c} 1}$ & 26 & 0 & 6.57 & 0 & 0.398 & 14 & Reed and Shipley (1987) \\
\hline & $L_{\mathrm{c} 2}$ & 75 & 0 & 6.54 & 0 & 0.400 & 8 & Reed and Shipley (1987) \\
\hline \multirow[t]{2}{*}{ GalCer(d18:1/16:1) } & $L_{\mathrm{c} 1}$ & 0 & 0 & 5.17 & 0 & 0.435 & 28 & Haas and Shipley (1995) \\
\hline & $L_{\mathrm{c} 2}$ & 46 & 0 & 4.92 & 0 & 0.457 & 18 & Haas and Shipley (1995) \\
\hline \multirow[t]{2}{*}{ GalCer(d18:1/18:1) } & $L_{\mathrm{c} 1}$ & 21 & 0 & 5.65 & 0 & 0.414 & 20 & Reed and Shipley (1989) \\
\hline & $L_{\mathrm{c} 2}$ & 47 & 5.5 & 6.12 & 0.87 & 0.382 & $0^{\mathrm{a}}$ & Reed and Shipley (1989) \\
\hline \multirow[t]{2}{*}{ GalCer(d18:1/18:2) } & $L_{\mathrm{c} 1}$ & 0 & 0 & 5.52 & 0 & 0.423 & 27 & Reed and Shipley (1989) \\
\hline & $L_{\mathrm{c} 2}$ & 34 & 4.0 & 6.20 & 0.64 & 0.376 & $0^{\mathrm{a}}$ & Reed and Shipley (1989) \\
\hline \multirow[t]{3}{*}{ LacCer(d18:1/16:0) } & $L_{\mathrm{c} 1}$ & 20 & 0 & 5.25 & 0 & 0.491 & 39 & Saxena et al. (2000b) \\
\hline & $L_{\mathrm{c} 2}$ & 20 & 1.4 & 6.35 & 0.20 & 0.393 & $0^{\mathrm{a}}$ & Saxena et al. (2000b) \\
\hline & & 68 & 0 & 6.45 & 0 & 0.431 & 14 & Saxena et al. (2000b) \\
\hline $\mathrm{I}^{3} \mathrm{SO}_{3}$ GalCer(d18:1/16:0) & $L_{\mathrm{c}}$ & 20 & 0 & 6.38 & 0.0 & 0.412 & 20 & Saxena et al. (2000a) \\
\hline
\end{tabular}

Note. $\mathrm{d} 18: 1 \equiv$ sphing-4-enine (sphingosine).

a It is assumed that the chains are untilted (see text).

$(0-16: 0)_{2} \mathrm{Lac}_{3} \beta \mathrm{DG}$ are then very small, which is consistent with the data of Table 1 for the monoglycosyl diacylglycerols. On the other hand, for the maltose derivatives (O- $n: 0)_{2}$ MalßDG, maltotriose (O-18:0) ${ }_{2} \mathrm{Mtr} \beta \mathrm{DG}$, and dilactose (O-16:0) ${ }_{2} \mathrm{Lac}_{2} \beta \mathrm{DG}$, it is assumed that the $L_{\beta}$ phases are untilted, in analogy with the dialkyl monoglycosylglycerols. The resulting estimates for $d_{\mathrm{w}}$ and $n_{\mathrm{w}}$ indicate that the hydration levels of the $L_{\beta}$ gel phases are low $\left(n_{\mathrm{w}, \mathrm{max}} \approx 3-5 \mathrm{~mol} / \mathrm{mol}\right)$, which again is consistent with the results for the $L_{\beta}$ phases of the monoglycosyl dialkyl glycerols (see Table 4 ).

\section{1,2-Dialkyl-3- $\beta$-D-glucuronosyl-sn-glycerol}

Table 6 gives data for the gel phase of the carboxyl-bearing glycoglycerolipid (0-18:0) $)_{2}$ GlcUAßDG at $\mathrm{pH} 1.6$ where it is uncharged and at $\mathrm{pH} 10$ where it is negatively charged. By analogy with the other dialkyl glycoglycerolipids (see Table 1 ), it is assumed that the lipid chains in the $L_{\beta}$-phase are untilted: $\theta_{\mathrm{t}}=0$. At $20^{\circ} \mathrm{C}$, the degree of hydration deduced for the uncharged lipid $\left(n_{\mathrm{w}, \max } \approx 5 \mathrm{~mol} / \mathrm{mol}\right)$ is similar to that for other uncharged dialkyl glycoglycerolipids (cf. Table 4 ), whereas the charged lipid is more strongly hydrated $\left(n_{\mathrm{w}, \max } \approx 7 \mathrm{~mol} / \mathrm{mol}\right)$.

\section{Glycosphingolipids}

Small-angle and wide-angle X-ray data are available for the $L_{c}$ phases of some glycosphingolipids, particularly cerebrosides. Polymorphism is commonly found: the $L_{\mathrm{c} 1}$ phase is a metastable crystalline polymorph, whereas the $L_{\mathrm{c} 2}$ polymorph is the stable form. In most cases, a water dependence has not been performed but the results from the glycoglycerolipids suggest that the $L_{\mathrm{c}}$ phases of the neutral glycosphingolipids probably also are essentially anhydrous. Data for monoglycosylceramides and a diosylceramide are given in Table 7. Unless indicated otherwise, it is assumed that neither metastable nor stable $L_{\mathrm{c}}$ phases are hydrated (i.e., $n_{\mathrm{w}, \max }=0$ ). The tilt angles resulting from these calculations are mostly relatively small for the monoglycosylceramides, particularly for galactosyl ceramides with saturated $N$-acyl chains. From the results presented in Table 7 , it seems reasonable to assume that the chains of the stable $L_{\mathrm{c} 2}$ polymorph are not tilted. Indeed, for the $L_{\mathrm{c} 2}$ phases of GalCer(d18:1/18:1), GalCer(d18:1/18:2) and LacCer(d18:1/16:0), it is necessary to postulate a limited degree of hydration because the repeat spacing is somewhat greater than that predicted for the lipids completely without tilt (i.e., $\theta_{\mathrm{t}}=0$ ).

A water dependence has been performed for a negatively charged glycosphingolipid, namely sulphatide $\left(\mathrm{I}^{3} \mathrm{SO}_{3} \mathrm{GalCer}\right)$. It is found that the long spacing of the $L_{\mathrm{c}}$ phase is not changed by addition of water (Saxena et al., 2000a), and is therefore anhydrous. Data for this $L_{\mathrm{c}}$ phase are included in Table 7 . The tilt of the sulphatide chains is also relatively small.

\section{Conclusion}

When combined with data from wide-angle diffraction (and densitometry), X-ray long spacings in excess water are able to provide information on the bilayer thickness and hydration of the crystalline and gel phases of lipid bilayers. This is without performing the usual water dependence in a multilayer swelling experiment (see Eqs. (1)-(5)). This method has been applied previously in a limited number of cases (Köberl et al., 1998). The application here to the available database for diacyl and dialkyl glyceroglycolipids, and some glycosphingolipids, shows that the crystalline phases are almost anhydrous and that hydration of the gel phase is much less than that of the corresponding glycerophospholipids.

A caveat for gel-phase diacyl monoglycosyldiacylglycerols is that the chain-length dependence of the long spacing is less than would be expected for untilted chains (Sen et al., 1990; Mannock et al., 2001). Particularly the $1,2-(n: 0)_{2}$ Glc $\alpha$ DGs are anomalous, in 
that the wide-angle reflections are characteristic of an untilted $L_{\beta}$ phase but indicate no change in area per chain with chain length that could explain the low incremental changes in long spacing. Clearly direct determinations of chain tilts are needed in aligned glycolipid bilayers (cf. Tristram-Nagle et al., 1993), and also precise measurements of the chain-length dependence of the x-ray short spacings (cf. Sun et al., 1996).

\section{Acknowledgement}

I gratefully acknowledge Christian Griesinger and the Dept. for NMR-based structural biology for financial support.

\section{Appendix A.}

Chain-length dependence of the repeat spacing for phosphatidylcholine gel phases.

For the gel phase of disaturated phosphatidylcholines, both the degree of hydration $\left(n_{\mathrm{w}}\right)$ and the area per lipid molecule $\left(A_{1}\right)$ are independent of the lipid chain length (Tristram-Nagle et al., 1993; Sun et al., 1996). In addition, the X-ray long spacings, depend linearly on chain length, $n_{\mathrm{C}}$ (see Fig. A.1). Under these boundary conditions, differentiating Eq. (1) in the main text with respect to $n_{\mathrm{C}}$ gives the chain-length dependence of the long spacing as:

$\frac{\partial d_{100}}{\partial n_{C}}=\frac{2}{A_{1}}\left(\frac{\partial v_{1}}{\partial n_{C}}\right)$

For $\quad(n: 0)_{2} \mathrm{PCs} \quad$ at $19{ }^{\circ} \mathrm{C}, \quad \partial v_{1} / \partial n=0.02270 \pm 0.00014 \mathrm{~nm}^{3} / \mathrm{CH}_{2}$ (Tristram-Nagle et al., 1993). From Fig. A.1 and Eq. (A.1), the area per lipid is then: $A_{1}=0.485 \pm 0.012 \mathrm{~nm}^{2}$, which agrees reasonably well with the constant value of $A_{1}=0.473 \pm 0.006 \mathrm{~nm}^{2}$ deduced by Tristram-Nagle et al. (1993) from direct measurements of chain tilts for the individual chain lengths.

For phosphatidylcholine gel phases, both chain $\operatorname{tilt}\left(\theta_{\mathrm{t}}\right)$ and chain cross-sectional area $\left(A_{\mathrm{ch}}\right.$ - see Fig. 3$)$ vary with chain length in a compensating fashion, such that the lipid area $A_{1}$ remains constant. At $19^{\circ} \mathrm{C}$, the chain tilt ranges from $\theta_{\mathrm{t}}=32 \pm 0.5^{\circ}$ for $(16: 0)_{2} \mathrm{PC}$ to $\theta_{\mathrm{t}}=35 \pm 0.5^{\circ}$ for $(20: 0)_{2} \mathrm{PC}$ (Tristram-Nagle et al., 1993), whereas the apparent value deduced from Eq. (6) in the main text by assuming that $d_{\mathrm{CH}_{2}}^{\mathrm{O}}$ is constant is: $\theta_{\mathrm{t}}=43 \pm 1^{\circ}$. This result from the chain-length dependence of $d_{100}$ is clearly an overestimate, because $\theta_{\mathrm{t}}$ increases with increasing chain length.

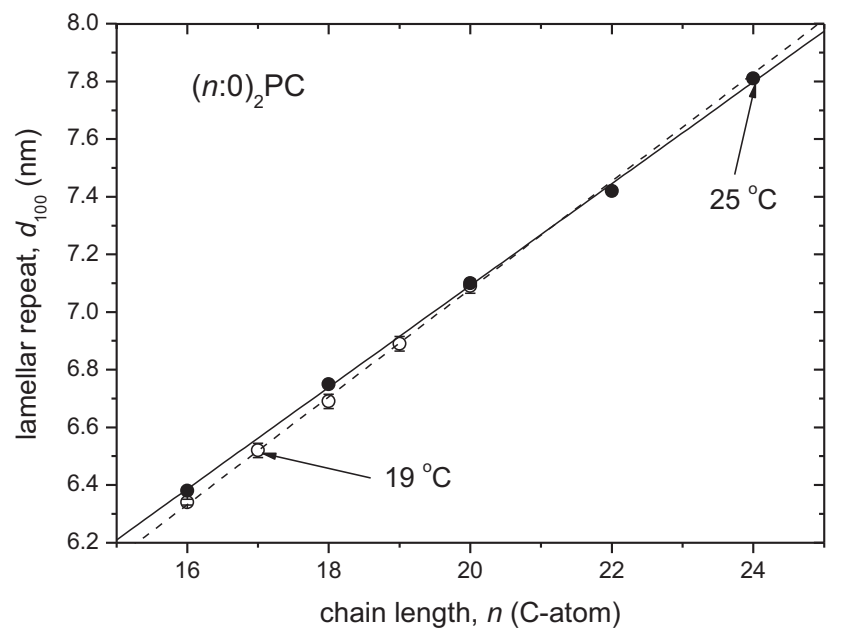

Fig. A.1. Dependence of the lamellar repeat distance, $d_{100}$, on lipid chain length, $n$, for 1,2-diacyl-sn-glycero-3-phosphocholines $\left((n: 0)_{2} \mathrm{PC}\right)$ in the $\mathrm{L}_{\beta^{\prime}}$ gel phase at $19{ }^{\circ} \mathrm{C}$ (Tristram-Nagle et al., 1993) and $25^{\circ} \mathrm{C}$ (Sun et al., 1996). The gradient of the linear regression at $19{ }^{\circ} \mathrm{C}$ is $\partial d_{100} / \partial n=0.187 \pm 0.004 \mathrm{~nm} / \mathrm{CH}_{2}$.
Whereas the chain cross-sectional area of the 1,2-diacyl-3- $\alpha$-Dglucosyl-sn-glycerol gel phases is reported not to vary with chain length (unlike the phosphatidylcholine gel phases - see Fig. 3), there are no wide-angle X-ray data available for the gel phases of the 1,2-diacyl-3- $\beta$-D-galactosyl-sn-glycerols. Therefore, it is interesting to explore the consequences of applying Eq. (A.1) (i.e., the assumption of constant $n_{\mathrm{W}}$ and $A_{\mathrm{l}}$ ) to the chain-length dependence of the long spacings for the gel phases of these glycolipids.

Densitometric data are not available for the diacyl glycolipids, but for (O- $n: 0)_{2} \mathrm{Glc} \beta D G s: \partial v_{l} / \partial n_{\mathrm{C}}=0.0226 \pm 0.0006 \mathrm{~nm}^{3} / \mathrm{CH}_{2}$ in the gel phase at $20^{\circ} \mathrm{C}$ (Marsh, 2010). Using this volumetric increment per $\mathrm{CH}_{2}$ group, and $\partial d_{100} / \partial n_{\mathrm{C}}=0.223 \pm 0.006$ and $0.232 \pm 0.007 \mathrm{~nm} / \mathrm{CH}_{2}$ from Table 1 , then yields areas per lipid of $A_{1}=0.41 \pm 0.02$ and $0.39 \pm 0.02 \mathrm{~nm}^{2}$ for the $(n: 0)_{2} \mathrm{Glc} \alpha \mathrm{DGs}$ and $(n: 0)_{2}$ GalßDGs, respectively, in the $L_{\beta}$ phase. These areas lie close to twice the cross-sectional area of a lipid chain: $2 A_{\mathrm{ch}}=0.404 \pm 0.008 \mathrm{~nm}^{2}$, which is the smallest value that the area per lipid may take, and would imply that the chains are not appreciably tilted in the gel phase of these diacyl glycolipids. That all chain lengths have rigorously zero tilt is, of course, contrary to the model with constant area per lipid, $A_{l}$.

Application of Eq. (A.1) to the gel phase of the (O-n:0) ${ }_{2} \mathrm{Glc} \beta D G s$ yields an apparent area per lipid: $A_{1}=0.36 \pm 0.04 \mathrm{~nm}^{2}$, which is less than the minimum possible value (i.e., $2 A_{\mathrm{ch}}$ ). A qualitatively similar, if not more anomalous, result is obtained for the $L_{\mathrm{c}}$ phase of the (O$n: 0)_{2}$ Gal $\beta D G s$. The assumption of constant $n_{\mathrm{w}}$ and $A_{\mathrm{l}}$ seems not to apply to the $L_{\beta}$ and $L_{c}$ phases of these dialkyl glycolipids, which calls into question whether it applies either to the diacyl glycolipids.

\section{References}

Cevc, G., Marsh, D., 1985. Hydration of non-charged lipid bilayer membranes. Theory and experiments with phosphatidylethanolamines. Biophys. J. 47, 21-31.

Haas, N.S., Shipley, G.G., 1995. Structure and properties of N-palmitoleoylgalactosylsphingosine (cerebroside). Biochim. Biophys. Acta 1240, 133-141.

Hinz, H.-J., Kuttenreich, H., Meyer, R., Renner, M., Fründ, R., Koynova, R., Boyanov, A.I., Tenchov, B.G., 1991. Stereochemistry and size of sugar head groups determine structure and phase behavior of glycolipid membranes - densitometric, calorimetric, and X-ray studies. Biochemistry 30, 5125-5138.

Koenig, B.W, Strey, H.H., Gawrisch, K., 1997. Membrane lateral compressibility determined by NMR and X-ray diffraction: effect of acyl chain polyunsaturation. Biophys. J. 73, 1954-1966.

Koynova, R.D., Tenchov, B., Kuttenreich, H., Hinz, H.-J., 1993. Structure and phase behavior of a charged glycolipid (1,2-O-dialkyl-3-O- $\beta$-D-glucuronosylsn-glycerol). Biochemistry 32, 12437-12445.

Köberl, M., Hinz, H.-J., Rapp, G., 1998. Temperature scanning simultaneous smalland wide-angle X-ray scattering studies on glycolipid vesicles: areas, expansion coefficients and hydration. Chem. Phys. Lipids 91, 13-37.

Kucerka, N., Nagle, J.F., Sachs, J.N., Feller, S.E., Pencer, J., Jackson, A., Katsaras, J., 2008. Lipid bilayer structure determined by the simultaneous analysis of neutron and X-ray scattering data. Biophys. J. 95, 2356-2367.

Kulkarni, K., Snyder, D.S., McIntosh, T.J., 1999. Adhesion between cerebroside bilayers. Biochemistry 38, 15264-15271.

Kuttenreich, H.L., Hinz, H.-J., Koynova, R., Tenchov, B., 1993. Different phase behaviour of the $s n-1$ and $s n-3$ stereoisomers of the glycolipid di-tetradecyl$\beta$-D-galactosylglycerol. Chem. Phys. Lipids 66, 55-62.

Luzzati, V., 1968. X-ray diffraction studies of lipid-water systems. In: Chapman, D. (Ed.), Biological Membranes. Academic Press, London, pp. 71-123.

Mannock, D.A., Collins, M.D., Kreichbaum, M., Harper, P.E., Gruner, S.M., McElhaney, R.N., 2007. The thermotropic phase behaviour and phase structure of a homologous series of racemic $\beta$-D-galactosyl dialkylglycerols studied by differential scanning calorimetry and X-ray diffraction. Chem. Phys. Lipids 148, 26-50.

Mannock, D.A., Harper, P.E., Gruner, S.M., McElhaney, R.N., 2001. The physical properties of glycosyl diacylglycerols. Calorimetric, X-ray diffraction and Fourie transform spectroscopic studies of a homologous series of 1,2-di-O-acyl-3-O( $\beta$-D-galactopyranosyl)-sn-glycerols. Chem. Phys. Lipids 111, 139-161.

Marsh, D., 2010. Molecular volumes of phospholipids and glycolipids in membranes Chem. Phys. Lipids 163, 667-677.

Marsh, D., 2011. Lateral order in gel and subgel phases of lipid membranes: wide-angle x-ray scattering, Chem. Phys. Lipids, doi:10.1016/ j.chemphyslip.2011.11.001, in press.

Marsh, D., 2012. Handbook of Lipid Bilayers. CRC Press, Boca Raton FL.

McIntosh, T.J., 1980. Differences in hydrocarbon chain tilt between hydrated phosphatidylethanolamine and phosphatidylcholine bilayers. Biophys. J. 29, 237-246 
McIntosh, T.J., Simon, S.A., 1994. Long- and short-range interactions between phospholipid/ganglioside GM1 bilayers. Biochemistry 33, 10477-10486.

Minamikawa, H., Hato, M., 1997. Phase behavior of synthetic phytanyl-chained glycolipid/water systems. Langmuir 13, 2564-2571.

Nagle, J.F., Tristram-Nagle, S., 2000. Structure of lipid bilayers. Biochim. Biophys. Acta 1469, 159-195.

Reed, R.A., Shipley, G.G., 1987. Structure and metastability of $N$ lignocerylgalactosylsphingosine (cerebroside) bilayers. Biochim. Biophys. Acta 896, 153-164.

Reed, R.A., Shipley, G.G., 1989. Effect of chain unsaturation on the structure and thermotropic properties of galactocerebrosides. Biophys. J. 55, 281-292.

Ruocco, M.J., Shipley, G.G., 1986. Thermal and structural behavior of natural cerebroside 3-sulfate in bilayer membranes. Biochim. Biophys. Acta 859, 246-256.

Saxena, K., Duclos, R.I., Sripada, P.K., Shipley, G.G., 2000a. Unusual hydration properties of C16:0 sulfatide bilayer membranes. Biophys. J. 79, 385-393.

Saxena, K., Duclos, R.I., Zimmermann, P., Schmidt, R.R., Shipley, G.G., 1999. Structure and properties of totally synthetic galacto- and gluco-cerebrosides. J. Lipid Res. 40, 839-849.

Saxena, K., Zimmermann, P., Schmidt, R.R., Shipley, G.G., 2000b. Bilayer properties of totally synthetic C16:0-lactosyl-ceramide. Biophys. J. 78, 306-312.

Schneider, M.F., Zantl, R., Gege, C., Schmidt, R.R., Rappolt, M., Tanaka, M., 2003. Hydrophilic/hydrophobic balance determines morphology of glycolipids with oligolactose headgroups. Biophys. J. 84, 306-313.

Seddon, J.M., Ces, O., Templer, R.H., Mannock, D.A., McElhaney, R.N., 2003. Structure and phase behaviour of synthetic glycolipids. Mol. Cryst. Liq. Cryst. 402, 77-84.

Seddon, J.M., Harlos, K., Marsh, D., 1983. Metastability and polymorphism in the gel and fluid bilayer phases of dilauroylphosphatidylethanolamine. J. Biol. Chem. $258,3850-3854$.
Sen, A., Hui, S.-W., Mannock, D.A., Lewis, R.N.A.H., McElhaney, R.N., 1990. Physical properties of glycosyl diacylglycerols. 2. X-ray diffraction studies of a homologous series of 1,2-di-O-acyl-3-O-( $\alpha$-D-glucopyranosyl)-sn-glycerols. Biochemistry 29, 7799-7804.

Smith, A.E., 1953. The crystal structure of the normal paraffin hydrocarbons. J. Chem. Phys. 21, 2229-2231.

Stinson, R.H., Boggs, J.M., 1989. Interdigitated lipid bilayers of long acyl species of cerebroside sulfate. An X-ray diffraction study. Biochim. Biophys. Acta 986, 234-240.

Sun, W.J., Tristram-Nagle, S., Suter, R.M., Nagle, J.F., 1996. Structure of gel phase saturated lecithin bilayers: temperature and chain length dependence. Biophys. J. 71, 885-891.

Tardieu, A., Luzzati, V., Reman, F.C., 1973. Structure and polymorphism of the hydrocarbon chains of lipids: a study of lecithin-water phases. J. Mol. Biol. 75, 711-713.

Tenchova, R., Tenchov, B., Hinz, H.-J., Quinn, P.J., 1996. Lamellar non-lamellar phase transitions in synthetic glycoglycerolipids studied by time-resolved X-ray diffraction. Liquid Cryst. 20, 469-482.

Tristram-Nagle, S., Liu, Y., Legleiter, J., Nagle, J.F., 2002. Structure of gel phase DMPC determined by X-ray diffraction. Biophys. J. 83, 3324-3326

Tristram-Nagle, S., Zhang, R., Suter, R.M., Worthington, C.R., Sun, W.J., Nagle, J.F., 1993. Measurement of chain tilt angle in fully hydrated bilayers of gel phase lecithins. Biophys. J. 64, 1097-1109.

Turner, D.C., Wang, Z.G., Gruner, S.M., Mannock, D.A., McElhaney, R.N., 1992. Structural study of the inverted cubic phases of di-dodecyl alkyl- $\beta-D-$ glucopyranosyl-rac-glycerol. J. Phys. II France 2, 2039-2063. 